Research Article

\title{
Study on Safety Control of Large-Section Roadway with High Stress and Broken Surrounding Rock
}

\author{
Wen-qing Peng (D, Hao Zhu, Qi Wang, and Gang Peng \\ China School of Resource Environment and Safety Engineering, Hunan University of Science and Technology, \\ Xiangtan 411201, China
}

Correspondence should be addressed to Wen-qing Peng; pengwenqing@163.com

Received 25 December 2020; Revised 6 January 2021; Accepted 9 January 2021; Published 29 January 2021

Academic Editor: Zhijie Zhu

Copyright (c) 2021 Wen-qing Peng et al. This is an open access article distributed under the Creative Commons Attribution License, which permits unrestricted use, distribution, and reproduction in any medium, provided the original work is properly cited.

\begin{abstract}
In order to solve the problem of difficult support of the roadway with high stress and large-section broken surrounding rock, this paper takes the subinclined shaft in Gaokeng mine of Jiangxi Province as the engineering background, analyzes the deformation mechanism and support mode of the roadway under the influence of mining through field investigation and mechanical derivation, and concludes that the stress concentration point of the roadway is in the middle point of roof and floor and the middle point of left and right sides. Through the modeling analysis of FLAC3D numerical software and the comparison of various support schemes, it is concluded that, after the combined support method of "anchor, net, and spray + grouting + full-section anchor cable + floor anchor cable" is adopted, the convergence of roof and floor is reduced by $508 \mathrm{~mm}$, and the convergence of two sides is reduced by $663 \mathrm{~mm}$. And, it is applied in engineering practice. The results show that the combined support scheme can effectively control the stability of the surrounding rock.
\end{abstract}

\section{Introduction}

Although China's coal mine mortality rate is decreasing year by year, the number of deaths by 2017 is as high as 375 , with a million-ton mortality rate higher than that in developed countries, as shown in Figure 1. With the increase of mining depth and intensity of coal resources, mine roof accidents are increasing, which seriously threaten the safety of coal mining. In the past five years, there have been 9009 coal mine deaths due to roof accidents in China, accounting for 38 percent. Therefore, strengthening the research of the coal mine roadway support is the focus of coal mine safety.

According to statistics, the mining depth of many mining areas in China has exceeded 600 800 $\mathrm{m}$, and many coal mines in China are expected to enter the mining depth of $1000 \sim 1500 \mathrm{~m}$ in the next 20 years. In recent years, with the improvement of heavy mining equipment and the promotion of the large mining-height working face, the roadway section increases from $10 \mathrm{~m}^{2} \sim 15 \mathrm{~m}^{2}$ to $18 \mathrm{~m}^{2} \sim 20 \mathrm{~m}^{2}$ and even larger, and the large-section roadway becomes the development trend of the modern mine. However, the large- section roadway has the disadvantages of easy settlement, easy instability, and difficult support. These factors affect the safety of the roadway, so how to take protective measures has always been a research topic of the industry. At present, there are many research results in the research of roadway safety control, such as Zhu et al. [1] through the on-site roof exploration test, using numerical simulation to analyze the failure process of the roadway roof, so as to elaborate the failure mechanism of the roadway roof, put forward bolt + wood combined support technology, and achieve good support effect. Yang et al. [2] analyzed the stress characteristics and crack evolution process of the roadway under different supporting forms for the soft-rock roadway and thus proposed the "bolt-mesh-spraying concrete + shell" combined support scheme, which effectively controlled the large deformation of the roadway. And, many scholars [3-6] proposed various combined support methods for complex geological conditions. Wang et al. [7] and Bai and Hou [8] believe that stress is an important factor in roadway deformation, and the former thinks that the causes of roadway safety are excessive pressure and stress concentration of the 


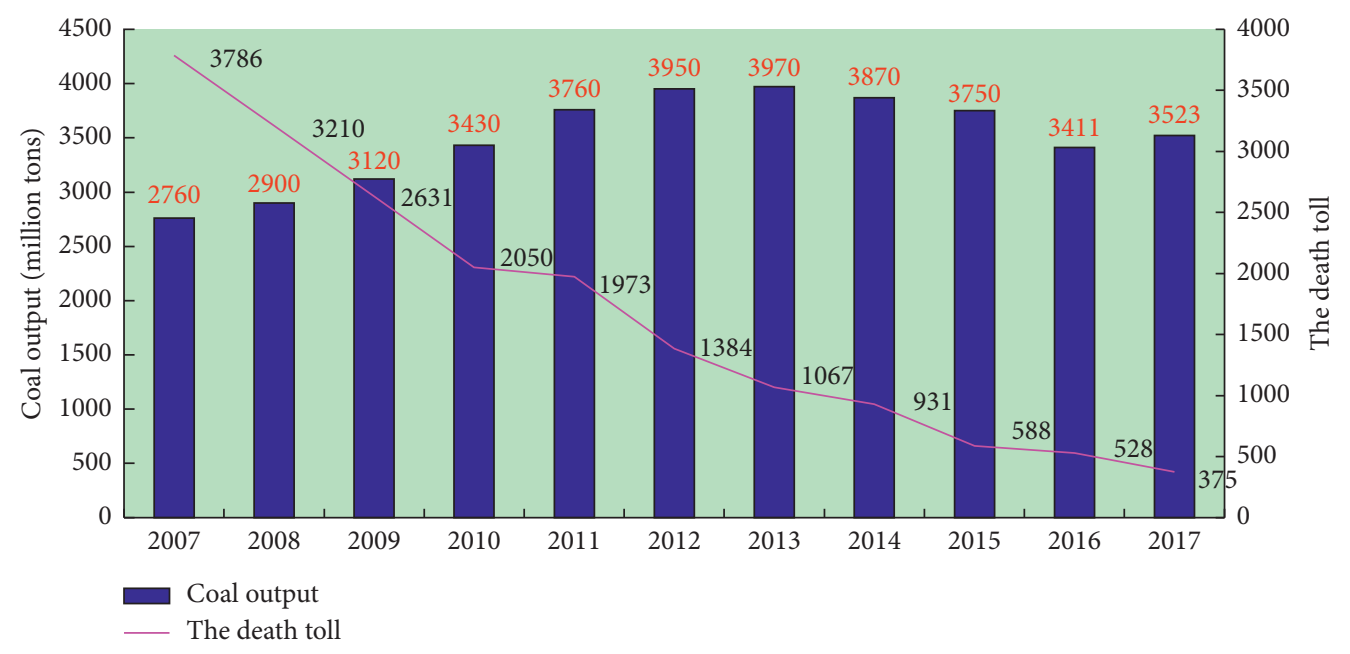

Figure 1: The death toll and coal output of coal mines in China.

surrounding rock. They optimized the optimal setting position of the pressure relief groove on the existing basis and effectively controlled the deformation of the surrounding rock. The latter thinks that the supporting technology of controlling the stress of the deep surrounding rock should start with controlling the stress and improving the strength of the broken zone of the surrounding rock. However, in the aspect of high stress and large-section roadway, the current research results are still relatively scarce. Zhang et al. [9] supported the concrete-filled steel tube in the high and deep stress roadway. Ping et al. [10] and many scholars [11-15] proposed that the main reason of the roadway broken ring is the instability of the structure under high stress, so it is particularly important to improve the stability and bearing capacity of the supporting structure. Therefore, on the basis of these methods, taking Gaokeng coal mine in China as the background, the failure mechanism of the subinclined shaft under the mining influence was analyzed in this paper, and the "anchor, mesh, and spray + grouting + full-section anchor cable + floor anchor cable" supporting scheme was put forward. Through the numerical simulation and field application, the results show that the combined support method can effectively complete the safety control of the large-section roadway.

\section{Stress Analysis of the Roadway Surrounding Rock under Mining Influence}

In practice, the characters of the roadway are complex and diverse, and the surrounding rock of the roadway is heterogeneous and discontinuous. There are many difficulties in establishing the mathematical model. Therefore, it is necessary to make some reasonable assumptions. Firstly, the roadway is assumed to be a circular roadway, and then, the surrounding rock is analyzed as a homogeneous and continuous elastic body, and the model is shown in Figure 2:

From elastic mechanics, the stress solution of the circular hole is as follows:

$$
\begin{aligned}
\sigma_{r}= & \frac{1}{2}\left(\sigma_{x}+\sigma_{y}\right)\left(1-\frac{r^{2}}{R^{2}}\right)-\frac{1}{2}\left(\sigma_{y}-\sigma_{x}\right) \\
& \left(1-4 \frac{r^{2}}{R^{2}}+3 \frac{r^{4}}{R^{4}}\right) \cos 2 \theta \\
\sigma_{\theta}= & \frac{1}{2}\left(\sigma_{x}+\sigma_{y}\right)\left(1+\frac{r^{2}}{R^{2}}\right)+\frac{1}{2}\left(\sigma_{y}-\sigma_{x}\right)\left(1+3 \frac{r^{4}}{R^{4}}\right) \cos 2 \theta,
\end{aligned}
$$

where $\sigma_{r}$ is the radial stress, $\sigma_{\theta}$ is the hoop stress, $\sigma_{x}$ is the horizontal stress, $\sigma_{y}$ is the normal stress, $r$ is the tunnel radius, $R$ is the radial distance from point $\mathrm{A}$ to roadway center, and $\theta$ is the angle between the OA direction and horizontal line.

It can be concluded from formulas (1) and (2) that the stress value has nothing to do with the mechanical parameters of the surrounding rock, but only with the horizontal stress $\sigma_{X}$ and vertical stress $\sigma_{y}$, and they are as follows:

$$
\begin{aligned}
\sigma_{y} & =\gamma H, \\
\sigma_{x} & =\lambda \sigma y .
\end{aligned}
$$

In the formula, $\gamma$ is the average bulk density of rock mass, $H$ is the burial depth, and $\lambda$ is the lateral pressure coefficient.

When the roadway design is completed, its $\gamma, H$, and $r$ have been determined, so the unknown quantities in equation (2) are $\lambda, R$, and $\theta$; when $R=r$ is considered, equation (2) can be expressed as follows:

$$
\sigma_{\theta}=\gamma H(1+\lambda)+2 \gamma H(1-\lambda) \cos 2 \theta .
$$

The function graph of equation (5) is drawn by Matlab, as shown in Figure 3.

It can be seen from Figure 3 that when it is about $0^{\circ}$, $90^{\circ}, 180^{\circ}$, and $270^{\circ}$, the function has extreme points, that is, the midpoint of the roof and floor of the roadway and 


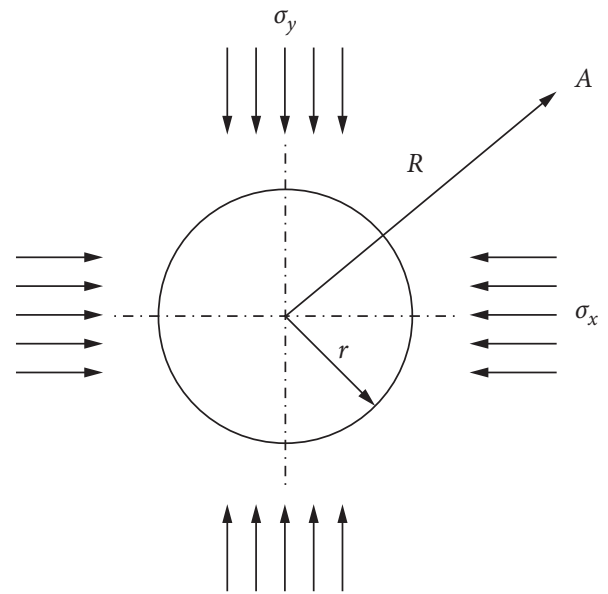

Figure 2: The computational mechanics model.

the midpoint of the left and right sides, so the most unfavorable position of the roadway is in the midpoint of the roof and floor and the midpoint of the left and right sides.

\section{Numerical Simulation of Stability Analysis of Bottom Dark Inclined Well under Mining Influence}

This simulation is based on the engineering geological conditions of the subinclined shaft in the Gaokeng Mine, Jiangxi Province. The subinclined shaft is arranged in the coal seam 3 floor, and the roadway section is $4.2 \mathrm{~m} \times 3.9 \mathrm{~m}$. The anchor net ladder spray, arch shed, reticulated shell, and other supporting methods are adopted, which are the main coal transportation systems at the three levels and below. The roadway is arranged in the coal seam 3 floor and bottom conglomerate layer from top to bottom, and the roadway is arranged in the bottom conglomerate, as shown in Figure 4.

In order to determine the loose range of the surrounding rock of the inclined shaft in the dark belt, the surrounding rock detection test was carried out. It can be seen that, in the surrounding rock of the inclined shaft roof in the dark belt, the cracks at $5 \mathrm{~m}-10 \mathrm{~m}$ are more developed, the surrounding rock is broken seriously, and there are obvious longitudinal cracks at $5 \mathrm{~m}$. In the wall rock, the most developed part of the crack is within $8 \mathrm{~m}$, and the other parts are relatively complete.

The roof and support of the roadway subsided as a whole. The roof fall occurred in many places from $-140 \mathrm{~m}$ to $-160 \mathrm{~m}$ elevation and showed the form of sharp tops, which indicated that the roof had a high horizontal stress state. And, at the elevation of $-160 \mathrm{~m}$ and the area below, it can be seen that there is an obvious fracture area in the part of the roof surrounding rock with the depth of $500 \mathrm{~mm}$. When drilling the anchor rod, the two sides bulge out into the roadway, spray layer falls off, phenomenon of spalling occurs, and damage is asymmetric. The damage of the side near the advancing direction of the working face is clearly serious. The most serious damage is found in the coal seam section where the underground inclined shaft passes through the bottom groove, and the spalling depth of the right-side slope is more than $1400 \mathrm{~mm}$, as shown in Figure 5. The floor heave is obvious, and the extrusion converges at the bottom corner.

The lithology classification and mechanical parameters of this simulation model are shown in Table 1. The specific model is shown in Figure 6.

Cyclic excavation of coal seam 3 is carried out during the calculation because the influence of coal seam excavation on the subinclined shaft is a dynamic process. In order to describe the cross mining process, considering the advance abutment pressure in front of the work $5 \sim 10 \mathrm{~m}$, so taking the overlying coal seam working face and the bottom plate at the horizontal distance of $40 \mathrm{~m}$ and $10 \mathrm{~m}$, the stress and plastic zone of the dark inclined shaft are analyzed.

It can be seen from Figures 7 and 8 that, during the whole excavation process, the vertical stress changes of the two sides are greater than the horizontal stress changes of the roof and floor. In the process of advancing, the vertical stress is mainly concentrated in the deep left side, and after the working face is pushed, the vertical stress changes to be concentrated in the deep right side. The shear stress has also changed greatly in the process of advancing. The shear stress of the bottom corner of the left side and the top corner of the right side increases at the beginning of the advancing process. After the working face is pushed, the shear stress of the top corner of the left side and the bottom corner of the right side increases, and the maximum value is larger than before. The change of the plastic zone reveals the process of roadway failure and is closely related to the change of stress. The first failure area is at the bottom corner of the left side and the top corner of the right side. With the advance of the working face and shortening of the horizontal distance from the dark inclined shaft, the two sides continue to damage. The top angle of the left side and the bottom angle of the right side are also seriously damaged, which leads to the increase of the hanging length of the roof and floor, and finally, the roof and floor begin to be seriously damaged.

In the process of excavation, the displacement measuring points are arranged at the midpoint of the roof and floor and the midpoint of the two sides, and the monitoring results are 


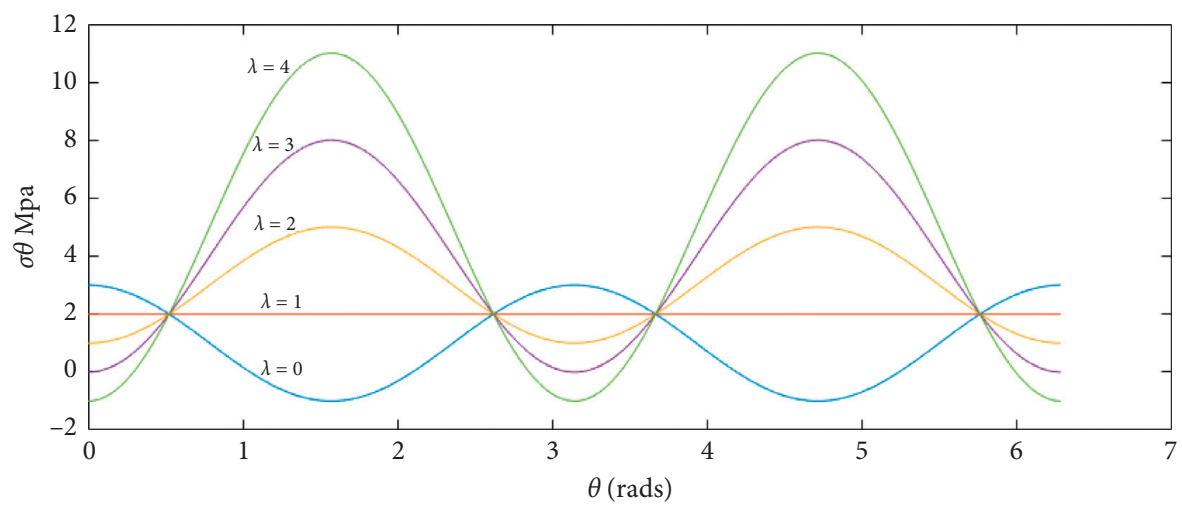

Figure 3: $\sigma_{\theta}$ stress distribution of the surrounding rock when $\lambda=0 \sim 4, \theta=0 \sim 2 \pi$, and $R=r$.

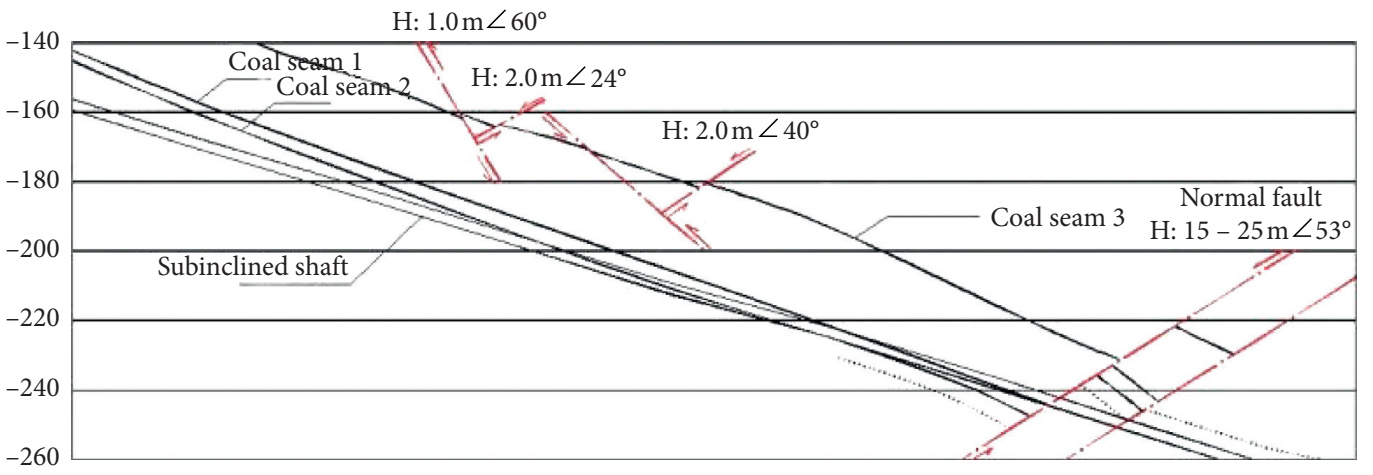

FIGURE 4: The space position relationship between the subinclined shaft and coal seam.

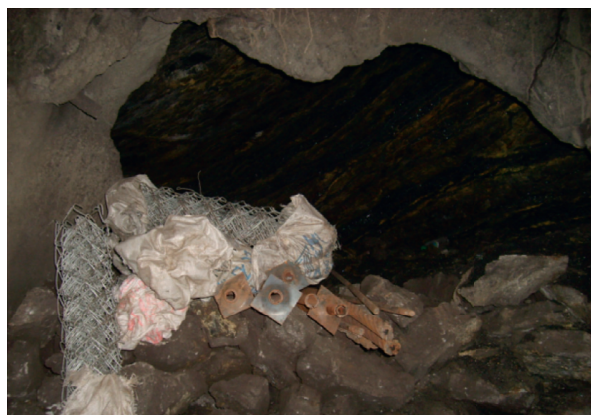

Left side

(a)

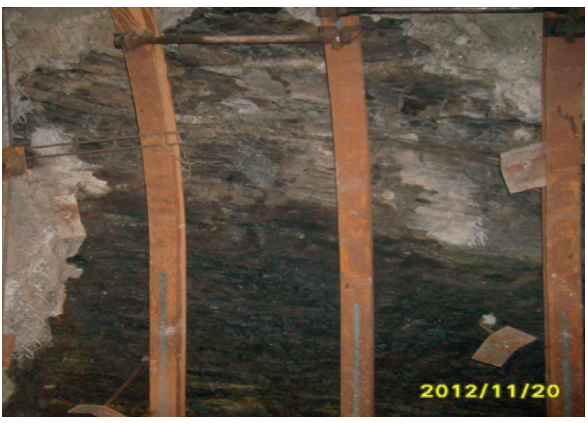

Right side

(b)

Figure 5: The damage of the surrounding rock. (a) Left side. (b) Right side.

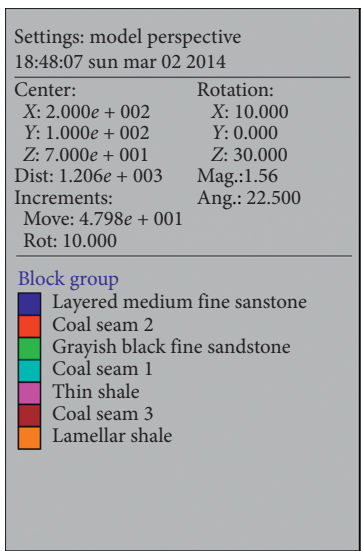

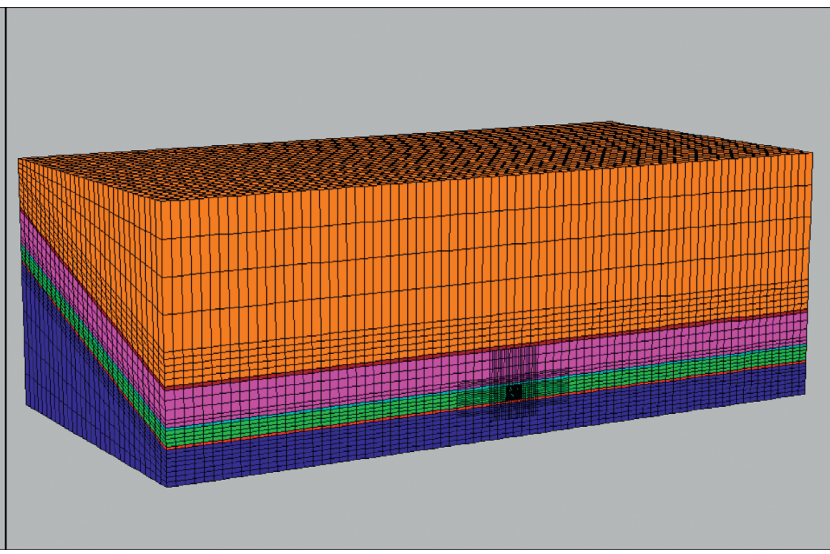

Figure 6: The model mesh map. 
TABLE 1: Mechanics calculation parameters of strata.

\begin{tabular}{|c|c|c|c|c|c|c|}
\hline Name & $\begin{array}{l}\text { Bulk modulus } \\
\mathrm{B}(\mathrm{GPa})\end{array}$ & $\begin{array}{l}\text { Shear modulus } \\
\qquad S(\mathrm{GPa})\end{array}$ & $\begin{array}{l}\text { Cohesion } \\
C(\mathrm{MPa})\end{array}$ & $\begin{array}{c}\text { Internal friction } \\
\text { angle } \Phi\left(^{\circ}\right)\end{array}$ & $\begin{array}{c}\text { Tensile strength } \\
R_{\mathrm{t}}(\mathrm{MPa})\end{array}$ & $\begin{array}{c}\text { Density } \\
\gamma\left(\mathrm{g} \cdot \mathrm{cm}^{-3}\right)\end{array}$ \\
\hline Lamellar shale & 6.79 & 4.47 & 2.65 & 31 & 1.20 & 2.50 \\
\hline Sweeping groove coal seam & 4.15 & 1.36 & 1.10 & 19 & 0.60 & 1.40 \\
\hline Thin shale & 6.79 & 4.47 & 2.65 & 31 & 1.20 & 2.50 \\
\hline Coal seam 1 & 4.15 & 1.36 & 1.10 & 19 & 0.60 & 1.40 \\
\hline Grayish-black fine sandstone & 21.00 & 10.23 & 4.25 & 39 & 1.85 & 2.64 \\
\hline Coal seam 2 & 4.15 & 1.36 & 1.10 & 19 & 0.60 & 1.40 \\
\hline Layered medium-fine sandstone & 21.00 & 10.23 & 4.25 & 37 & 1.85 & 2.64 \\
\hline
\end{tabular}

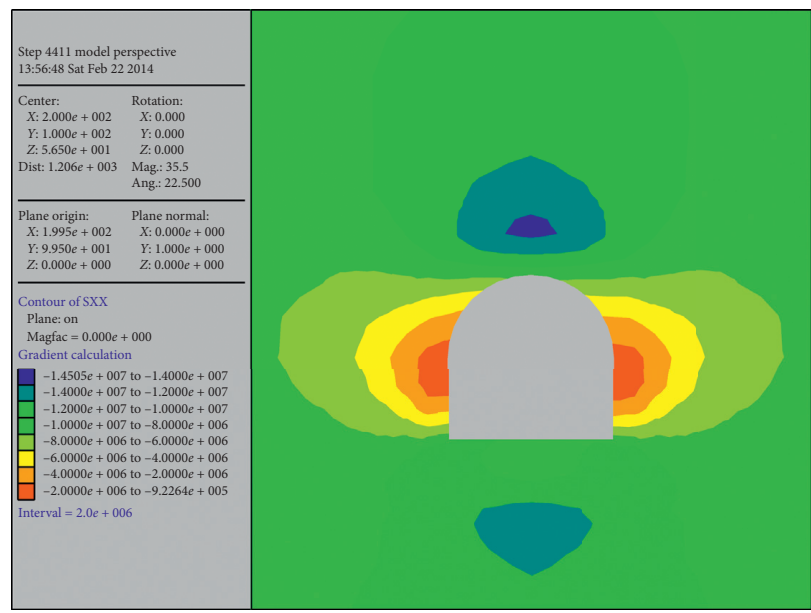

(a)

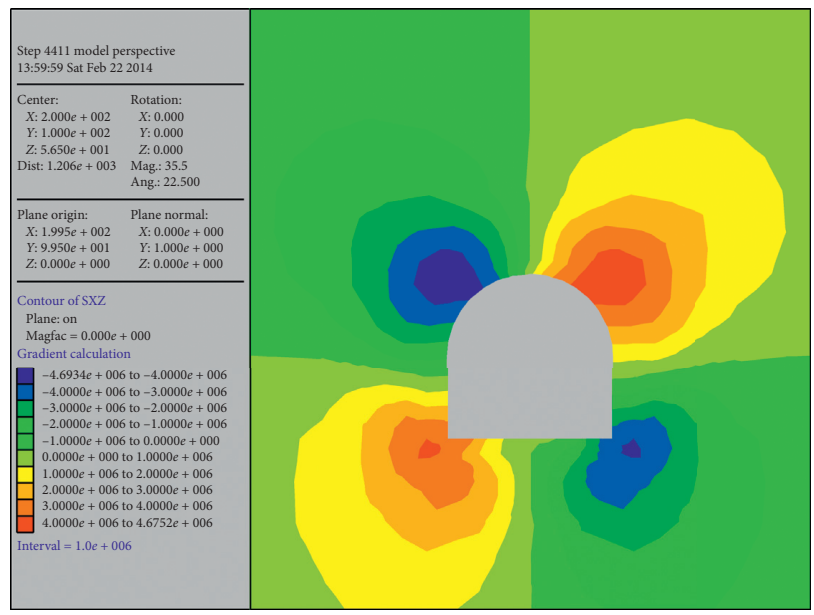

(c)

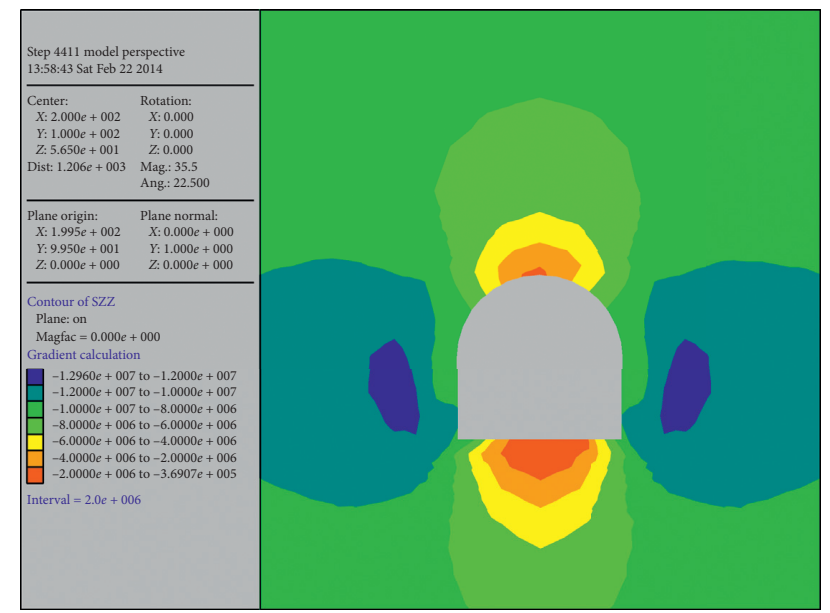

(b)

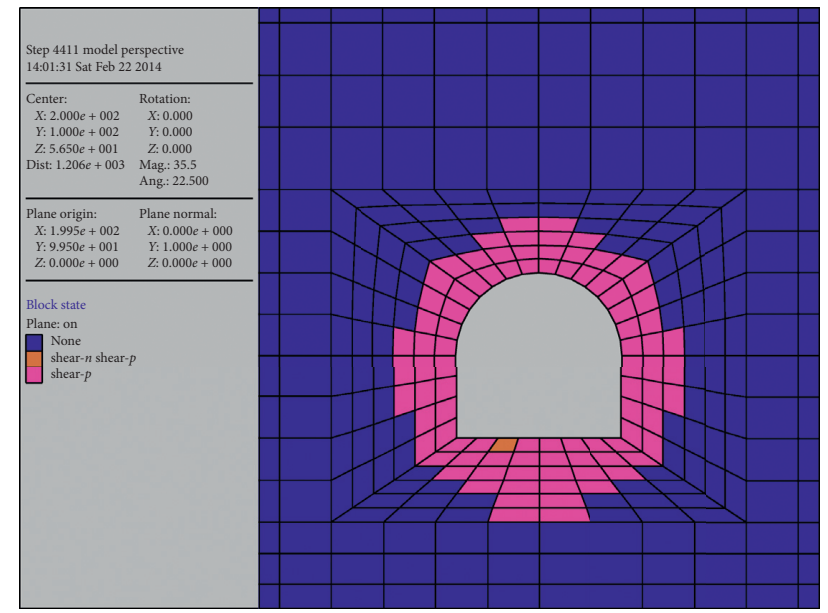

(d)

Figure 7: The stress state of the roadway after initial excavation. (a) Horizontal stress nephogram. (b) Vertical stress nephogram. (c) Shear stress nephogram. (d) Distribution of the plastic area.

calculated to obtain the deformation of the surrounding rock of each excavation roadway. In the process of working face advancing, the destruction of the two sides is prior to the destruction of the roof and floor, so the deformation of the two sides in the process of working face pushing close to the subinclined shaft is greater than that of the roof and floor. When the working face is pushed above the subinclined shaft because the two sides have been destroyed, the roof and floor begin to be seriously damaged due to the increase of the hanging length. In order to investigate the circumferential stress variation process around the inclined shaft in detail, measuring points are arranged at $3 \mathrm{~m}$ depth of the two sides to monitor the vertical stress variation, and the monitoring results are shown in Figure 9.

It can be seen from Figure 10 that the vertical stress of the two sides is greatly affected by mining and changes rapidly. It 


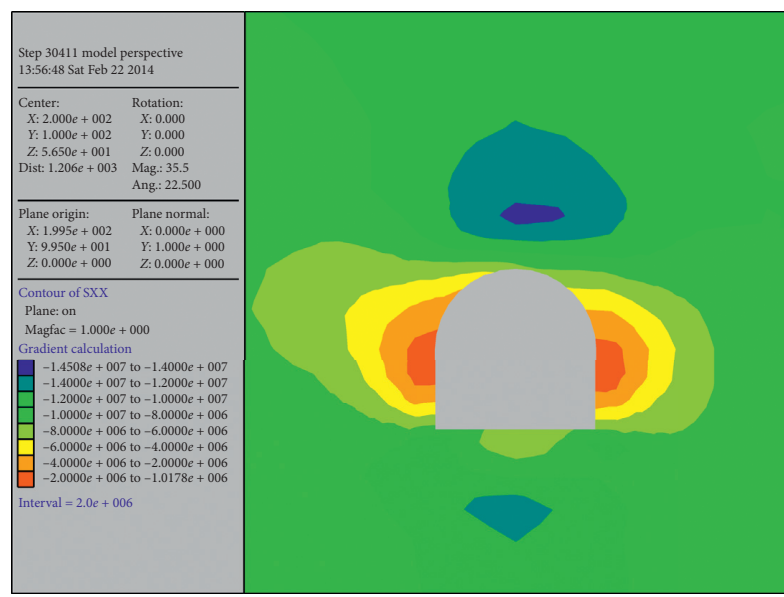

(a)

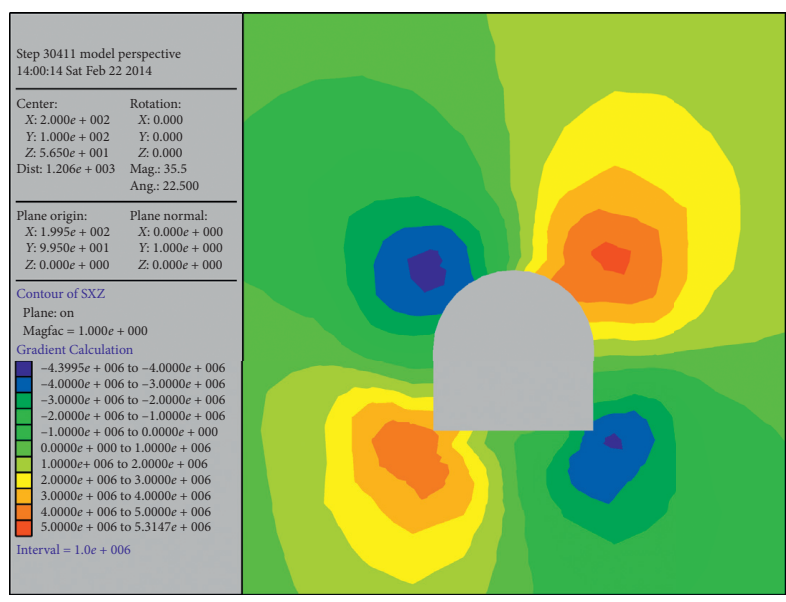

(c)

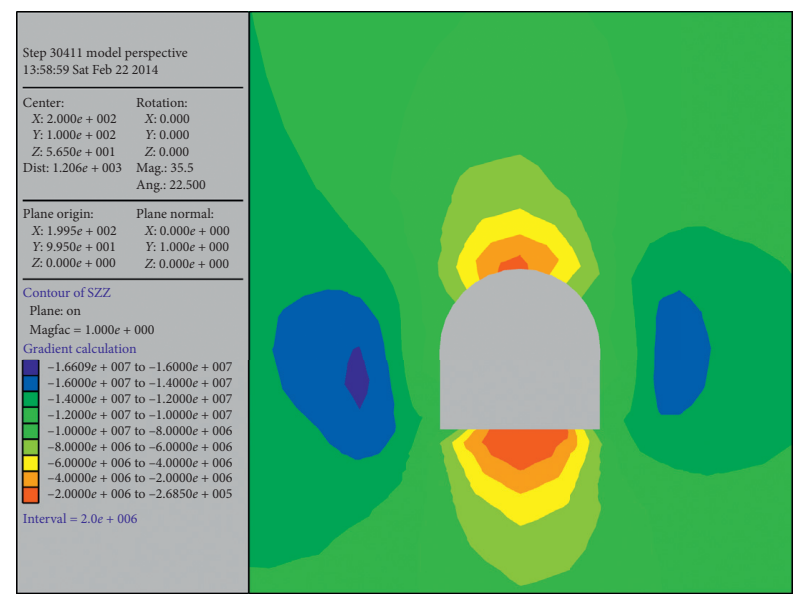

(b)

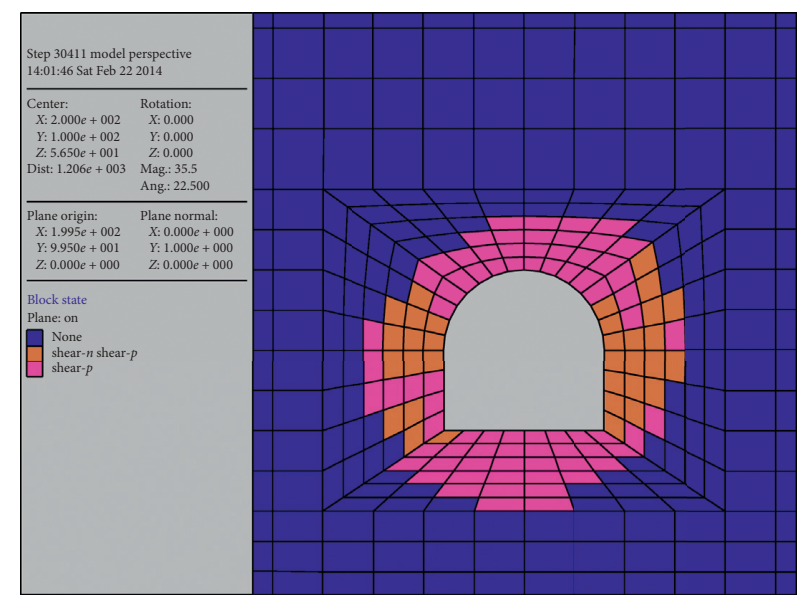

(d)

Figure 8: The stress state of the roadway. (a) Horizontal stress nephogram. (b) Vertical stress nephogram. (c) Shear stress nephogram. (d) Distribution of the plastic area.

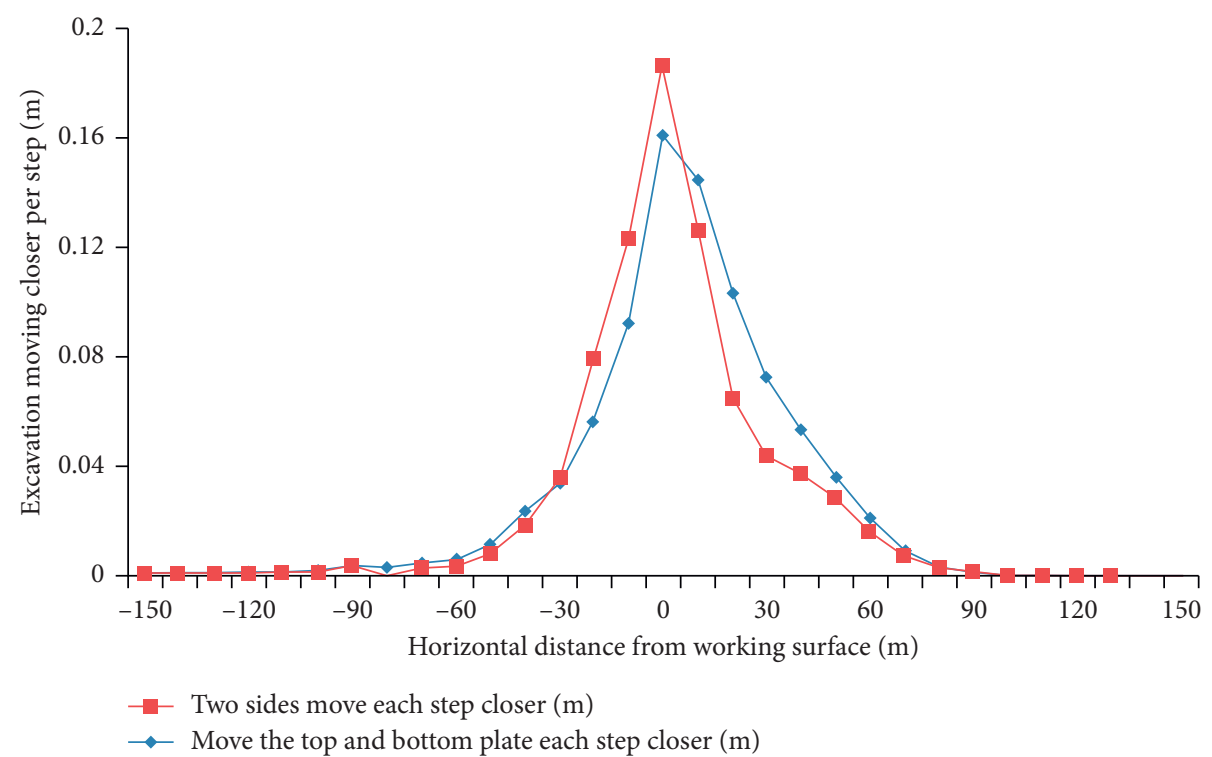

Figure 9: Deformation of roof and floor and sides per mining step. 


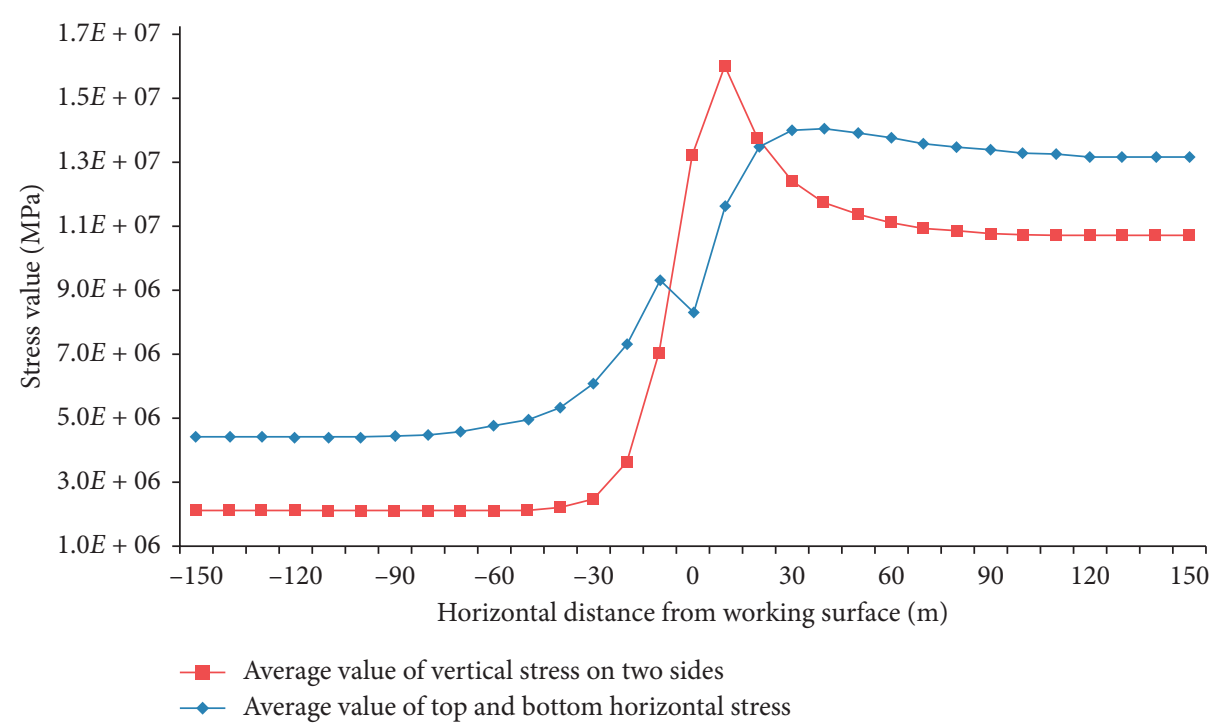

FIgURE 10: Circumferential stress distribution in 3 meters deep surrounding rock.

begins to rise rapidly at $30 \mathrm{~m}$ and reaches the peak of $16 \mathrm{MPa}$ at $10 \mathrm{~m}$. The horizontal stress of the roof and floor is less affected, which has reached the peak of $14 \mathrm{MPa}$ and then began to decline, and there is a rebound at $15 \mathrm{~m}$. The biggest difference is that the horizontal stress of the roof and floor and the vertical stress of the two sides did not rise back to the initial state after the working face was pushed. The main reason is that the surrounding rock enters the plastic zone due to the influence of high stress, and the rock enters the postpeak strength stage, which has lost its bearing capacity.

\section{Study on Surrounding Rock Control Technology of the Dark Inclined Shaft under Mining Influence}

4.1. Conceptual Design. This numerical simulation mainly analyzes the numerical calculation models of different supporting methods in the process of coal seam 3 . The model still uses the numerical calculation model established above. For comparison, four schemes are determined in this simulation, as shown in Table 2.

4.2. Numerical Simulation Result Analysis. It can be seen from Figures 11-15 that, in the case of no support, the roadway deformation is serious, the roadway roof and floor convergence is $792 \mathrm{~mm}$, and the two sides' convergence is $850 \mathrm{~mm}$. After using "anchor, net, and spray + grouting" support, the roof and floor movement is reduced by $223 \mathrm{~mm}$, and the two sides' movement is reduced by $414 \mathrm{~mm}$. It can be seen that the surrounding rock of the two sides of the roadway is under certain control, but the control effect of floor heave is not obvious. At this time, the floor heave of the roadway is $334 \mathrm{~mm}$, which becomes the main part of the roadway deformation. After adopting "anchor, net, and spray + grouting + full-section anchor cable" support, the displacement of the roof and floor is reduced by $427 \mathrm{~mm}$, and the displacement of two sides is reduced by $642 \mathrm{~mm}$. The
TABLE 2: The table of support schemes.

\begin{tabular}{|c|c|}
\hline $\begin{array}{l}\text { Serial } \\
\text { number }\end{array}$ & Support mode \\
\hline Scheme 1 & No support \\
\hline Scheme 2 & Bolt + metal mesh + shotcrete support \\
\hline Scheme 3 & Bolt + anchor cable + metal mesh + shotcrete support \\
\hline Scheme 4 & $\begin{array}{c}\text { Bolt }+ \text { anchor cable }+ \text { metal mesh }+ \text { shotcrete }+ \text { floor-anchor } \\
\text { cable support }\end{array}$ \\
\hline
\end{tabular}

deformation of the surrounding rock of the roadway is controlled effectively. After adopting supporting scheme 4, the deformation was further controlled, in which the displacement of the roof and floor was reduced by $508 \mathrm{~mm}$, the displacement of the two sides was reduced by $663 \mathrm{~mm}$, and the surrounding rock of the roadway remained stable. Therefore, it was reasonable to adopt the support method of "anchor, net spray+grouting + full-section anchor cable+floor anchor cable."

\section{Engineering Application}

In the subinclined shaft with the elevation of $-205 \mathrm{~m}--240 \mathrm{~m}$, because it has entered the floor of coal seam 3 , the surrounding rock is relatively complete, but the vertical distance from coal seam 3 is small, so it is still necessary to strengthen the support. The specific layout is shown in Figure 16.

The cross method is used to monitor the surface deformation of the roadway. In order to analyze the supporting effects of three different supporting schemes, the observation results are shown in Figures 17 and 18.

It can be seen from the displacement monitoring map that the deformation of the dark inclined shaft changes greatly between the 25th day of monitoring and the 50th day of monitoring. At this time, the horizontal distance between the working face and floor roadway is $40 \mathrm{~m}$ to $-10 \mathrm{~m}$, and the working face has no effect on the stability of the surrounding rock of the dark inclined shaft. The deformation of station 2 is 

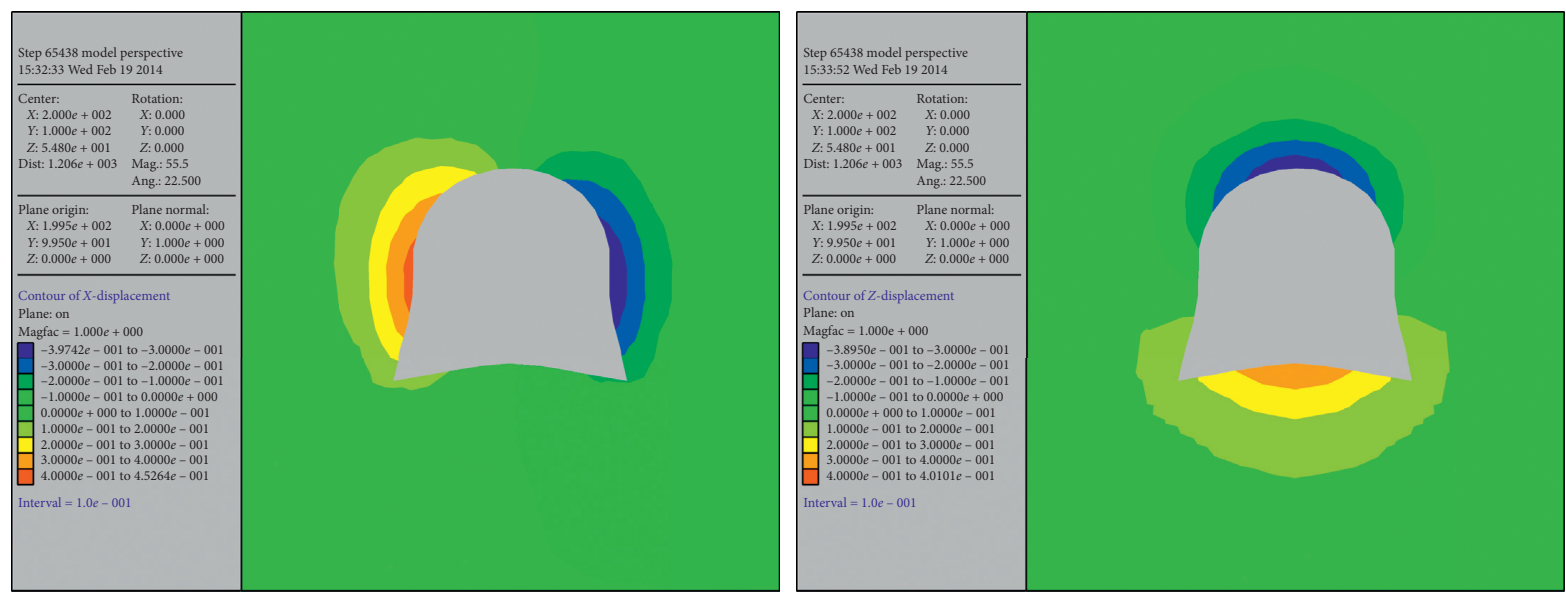

Figure 11: The nephograms of displacement (Scheme 1).
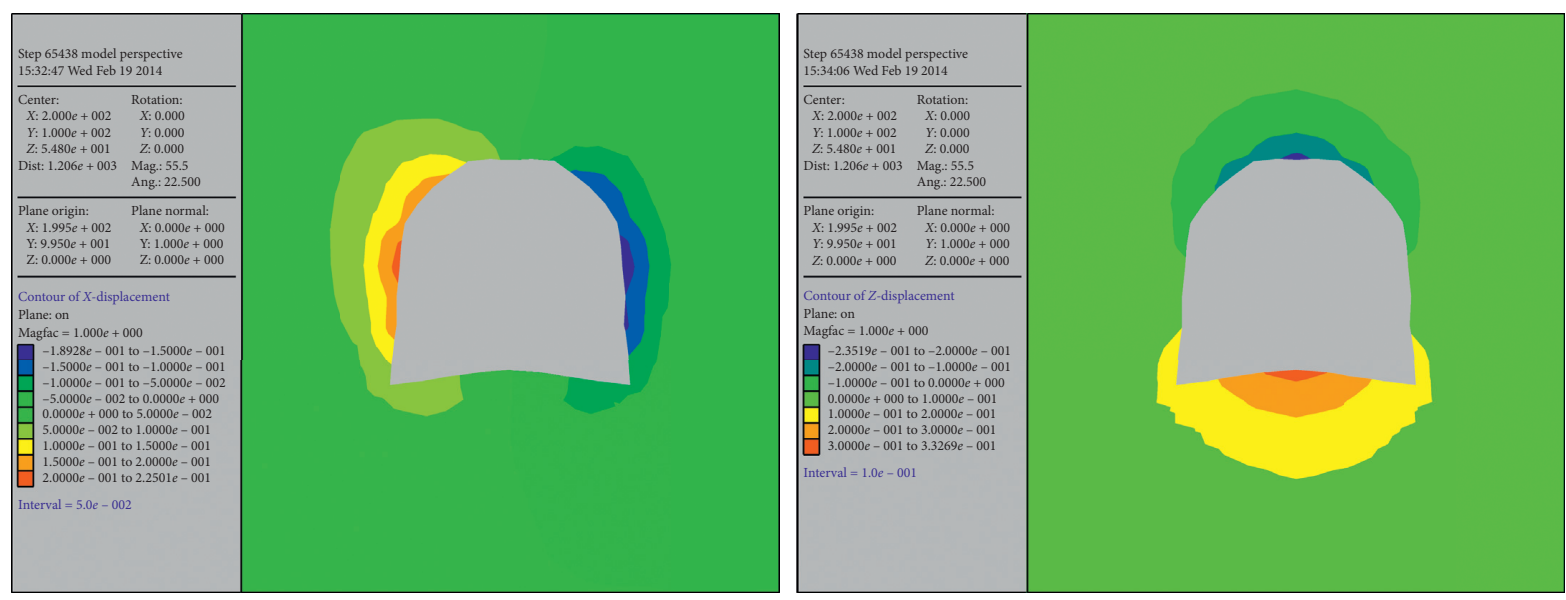

FIGURE 12: The nephograms of displacement (Scheme 2).
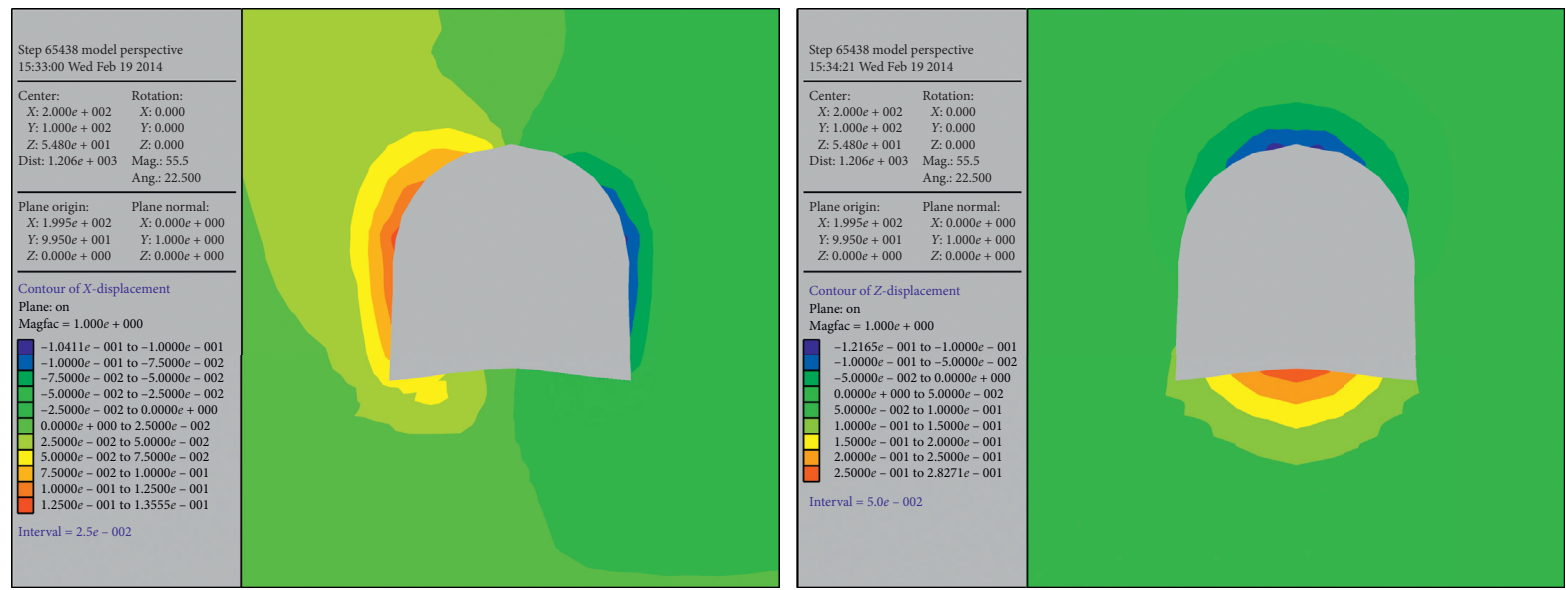

Figure 13: The nephograms of displacement (Scheme 3).

less than the other two, which shows that grouting has a significant effect on improving the stability of the roadway. The deformation rate of station 3 is faster, which is related to the small vertical distance between the measuring point position and overlying coal seam. However, because the spacing between the anchor cables is encrypted in the support scheme, the cumulative deformation is still close to that of station 1 . In short, according to the monitoring results, the 

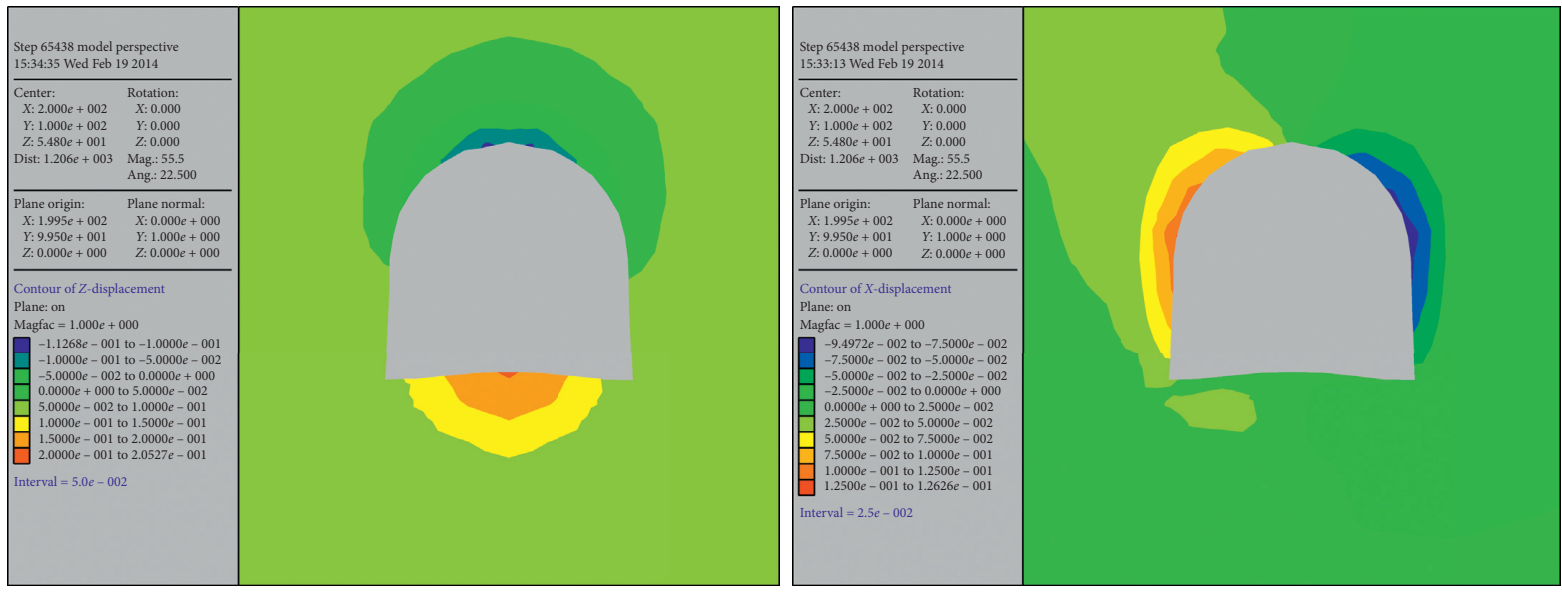

FIGURE 14: The nephograms of displacement (Scheme 4).

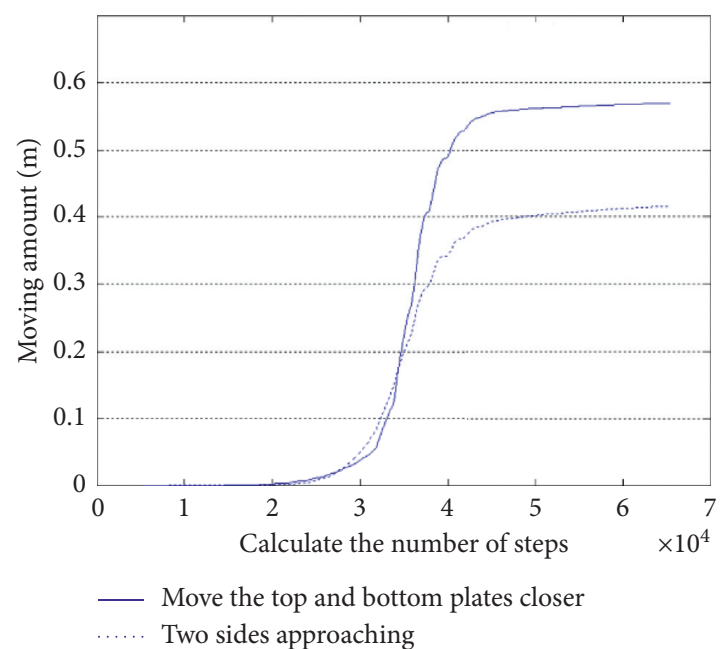

(a)

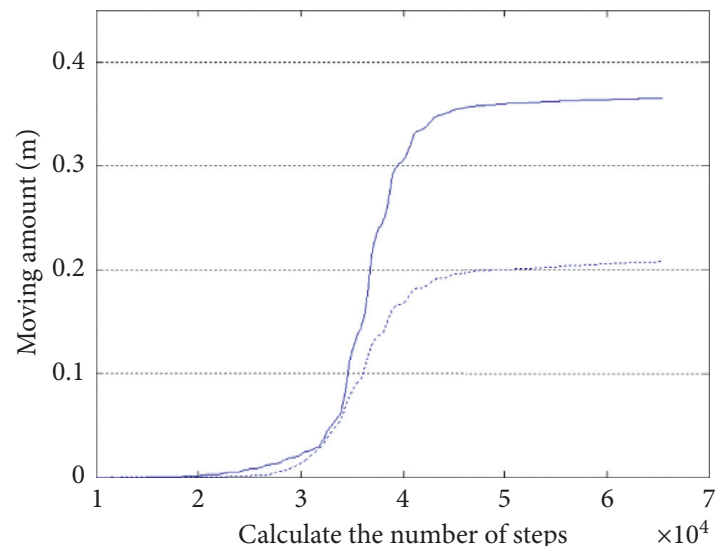

- Move the top and bottom plates closer

..... Two sides approaching

(c)

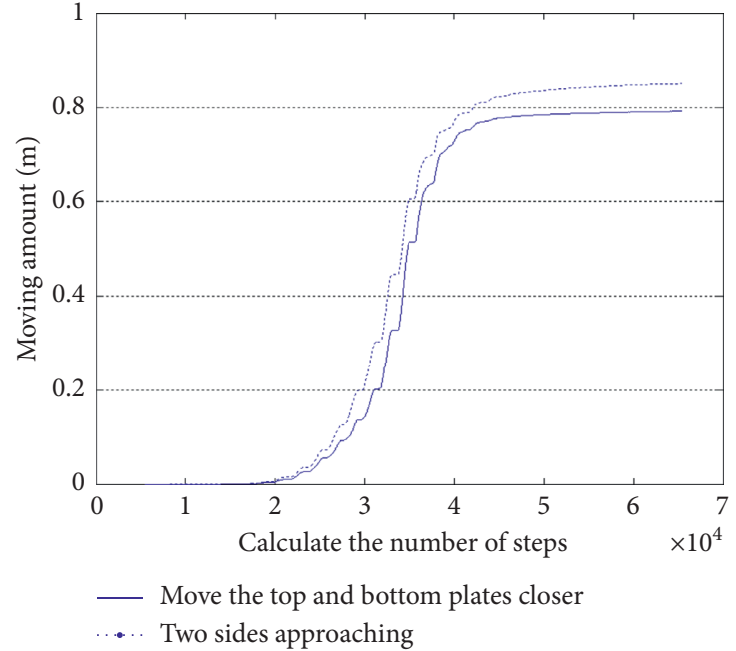

(b)

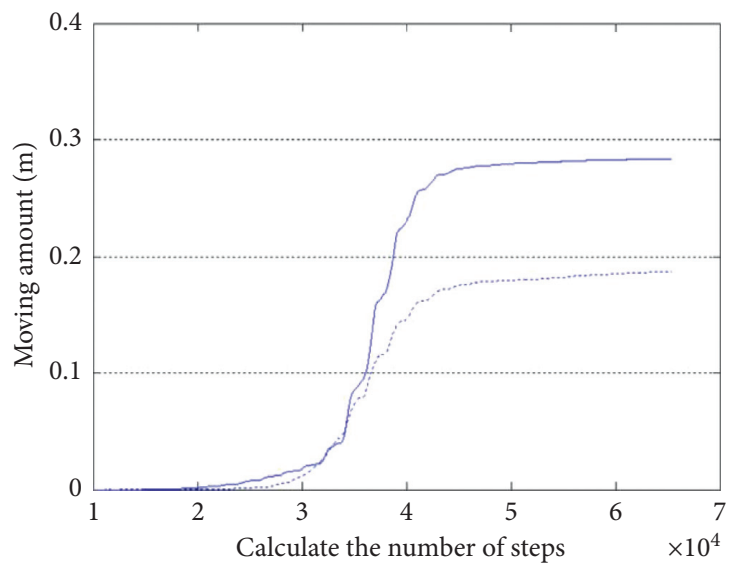

- Move the top and bottom plates closer

... Two sides approaching

(d)

Figure 15: The displacement curve with each scheme. (a) No support. (b) Bolt-mesh shotcreting support. (c) Anchor mesh shotcreting + anchor cable. (d) Anchor mesh shotcreting + anchor cable + bottom anchor cable. 

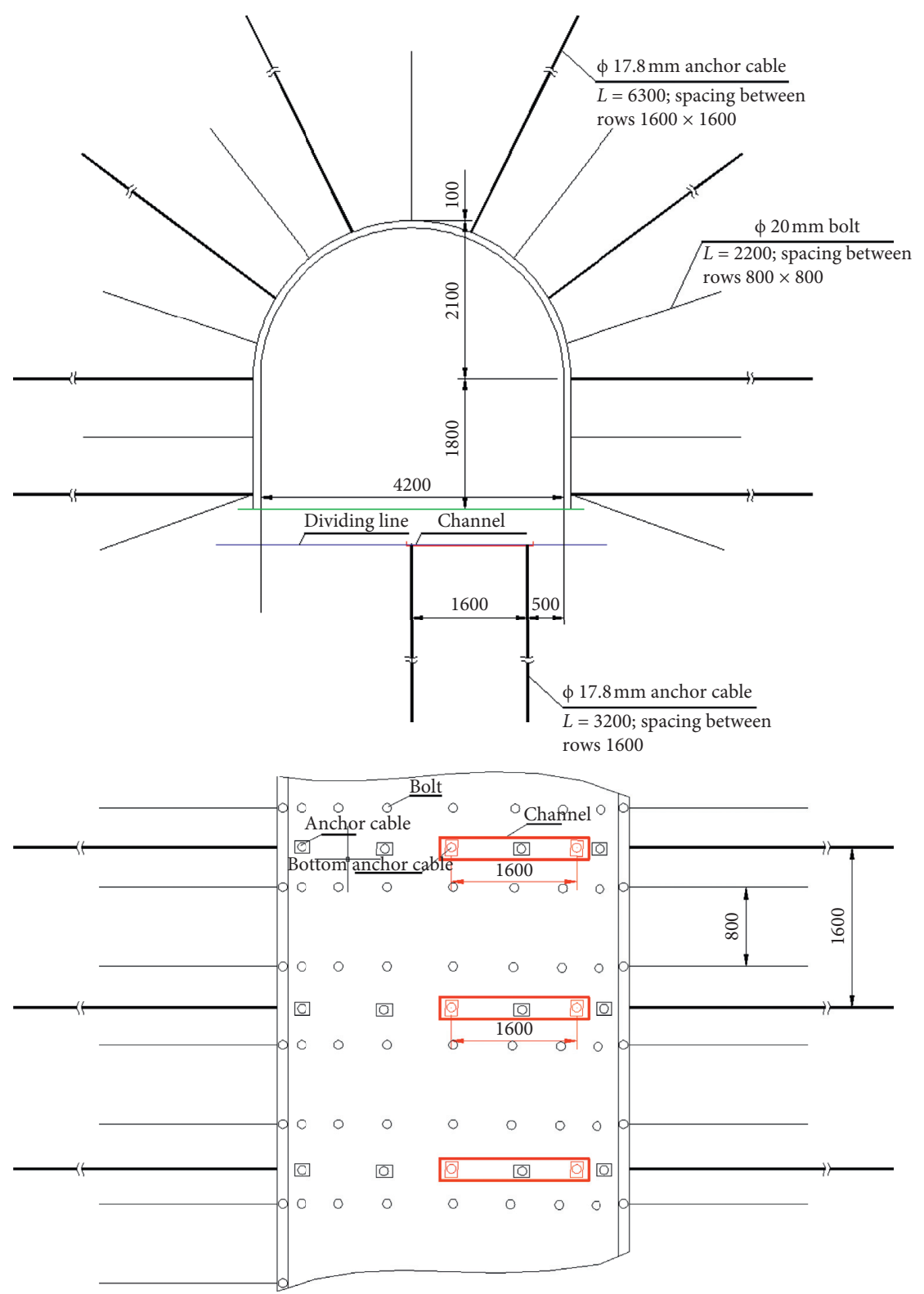

Figure 16: The diagram of the section support.

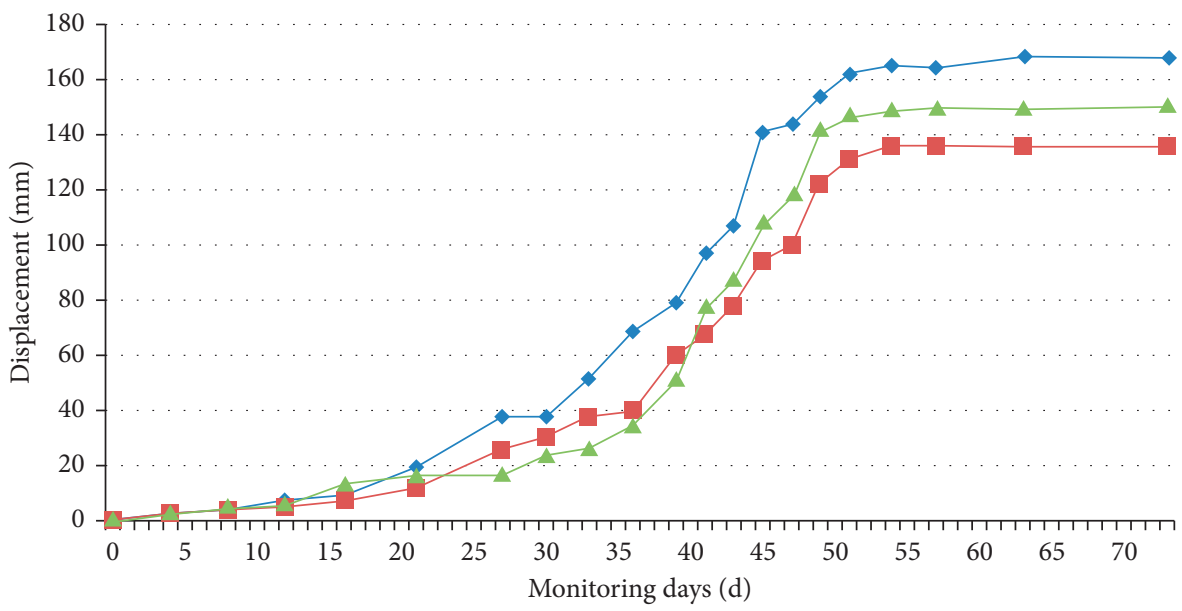

- Station 1

- Station 2

$\rightarrow$ Station 3

FIgURE 17: The displacement monitor of the roof and floor. 


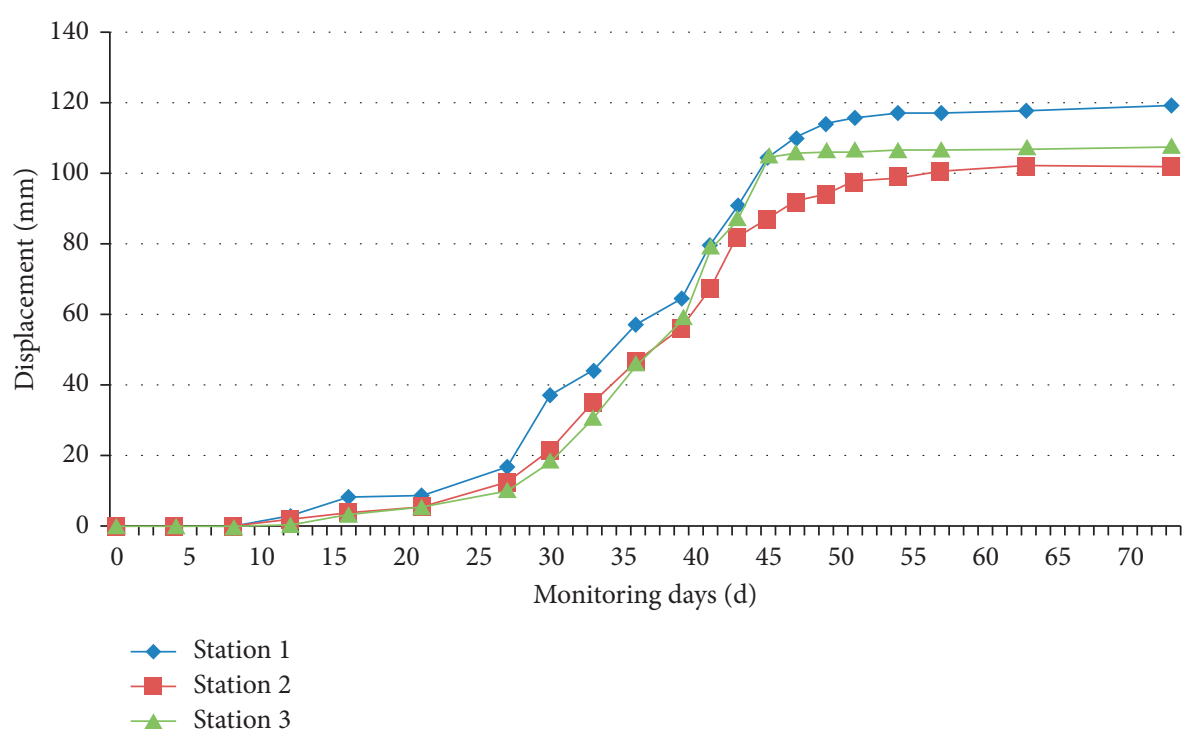

Figure 18: The displacement monitor of sides.

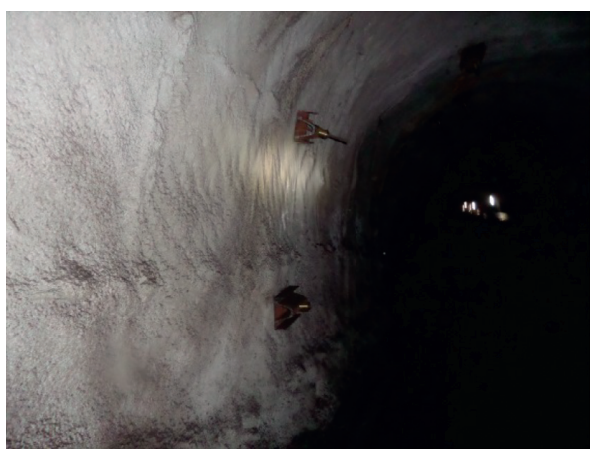

(a)

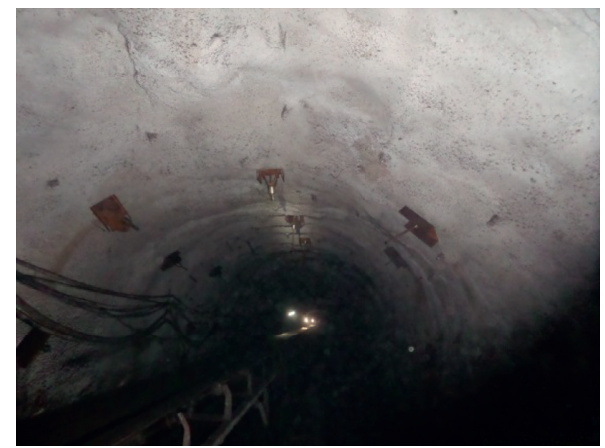

(b)

FIGURE 19: Support graphs.

maximum displacement of the roof and floor is $168.5 \mathrm{~mm}$, the displacement of left and right sides is $119.3 \mathrm{~mm}$, and the deformation of the surrounding rock is within the allowable range, which fully proves that the combined support technology of anchor, net, and spray + grouting + full-section anchor cable is feasible and can maintain the long-term stability of the floor dark inclined shaft. The support for the actual project is shown in Figure 19.

\section{Conclusions}

(1) The failure of the roadway supporting structure and the serious deformation of the roadway itself are due to the high stress level of the surrounding rock in the roadway, so floor heave, spalling, and tipping are produced.

(2) Under the influence of disturbance in the process of excavation, the dark inclined shaft begins to deform at $60 \mathrm{~m}$ away from the working face, and the deformation is the largest at $10 \mathrm{~m}$ to $-10 \mathrm{~m}$ away from the working face, and the influence is the deepest, but the working face is pushed over $60 \mathrm{~m}$ and out of the influence range.

(3) Using the combined support method of "anchor, mesh, and shotcreting + grouting + full-section anchor cable," the maximum displacement of the top and bottom plate is $168.5 \mathrm{~mm}$, which is reduced by $64 \%$, and the displacement of the left and right side is $119.3 \mathrm{~mm}$, which is about $78 \%$ less, which shows that this support method plays a good role

\section{Data Availability}

The data used to support the findings of this study are available from the corresponding author upon request.

\section{Conflicts of Interest}

The authors declare that they have no conflicts of interest regarding the publication of this paper. 


\section{Acknowledgments}

This work was supported by the National Natural Science Foundation of China (51974118), Hunan Provincial Natural Science Foundation of China (2020JJ4305), and Scientific Research Fund of Hunan Provincial Education Department (18B226).

\section{References}

[1] D. Zhu, Y. Wu, Z. Liu, X. Dong, and Yu Jin, "Failure mechanism and safety control strategy for laminated roof of wide-span roadway," Engineering Failure Analysis, vol. 111, Article ID 104489, 2020.

[2] S.-Q. Yang, M. Chen, H.-W. Jing, K.-F. Chen, and B. Meng, “A case study on large deformation failure mechanism of deep soft rock roadway in Xin'An coal mine, China," Engineering Geology, vol. 217, pp. 89-101, 2017.

[3] F. He, B. Yang, S. Yin, X. Wang, and C. Tian, "Study on safety technology of anti-caving at a super-large section roadway with thick and fractural coal roof," Procedia Engineering, vol. 26, pp. 545-553, 2011.

[4] S. Du, D. Li, W. Yu, J. Zhang, and F. Liu, "Stability analysis and support control for a jointed soft rock roadway considering different lateral stresses," Geotechnical and Geological Engineering: An International Journal, vol. 38, no. 12, 2020.

[5] Q. Meng, L. Han, Y. Chen et al., "Influence of dynamic pressure on deep underground soft rock roadway support and its application," International Journal of Mining Science and Technology, vol. 26, no. 5, 2016.

[6] J. Kong, P. Chen, J. Chen, Q. S. Liu, and Z. Ma, "Research on support technology in deep roadway of huafeng mine," $A d$ vanced Materials Research, vol. 753-755, 2013.

[7] X. Wang, W. Luo, L. Qiu et al., "Unloading mechanism and design analysis of surrounding rock in deep high stress roadway," in IOP Conference Series: Earth and Environmental Science, vol. 428, no. 1, IOP Publishing, Article ID 012056, 2020.

[8] J.-B. Bai and C.-J. Hou, "Control principle of surrounding rocks in deep roadway and its application," Journal-China University of Mining and Technology-Chinese Edition, vol. 35, p. 145, 2006.

[9] J. Zhang, L. Liu, J. Cao, X. Yan, and F. Zhang, "Mechanism and application of concrete-filled steel tubular support in deep and high stress roadway," Construction and Building Materials, vol. 186, pp. 233-246, 2018.

[10] Z. Ping, M. Nianjie, J. Wei, and R. Jianju, “Combined support technology of large section roadway in high-stress fractured surrounding rock," Procedia Engineering, vol. 26, pp. 12701278, 2011.

[11] W.-Q. Peng, W.-J. Wang, and C. Yuan, "Supporting technology research in deep well based on modified terzaghi formula," Advances in Civil Engineering, vol. 2018, no. 10, pp. 1-6, 2018.

[12] S. Liu, Q. Zhu, H. Jia, and X. Li, "Characteristics and recognition of the dynamic response of strata interfaces to anchorage hole drilling in coal roadway roof," Journal of Mining \& Safety Engineering, vol. 34, no. 4, pp. 748-759, 2017.

[13] Y. Li, D. Zhang, Y. Song et al., "Experimental research of progressive damage of surrounding rock for soft fractured deep tunnel," Chinese Journal of Rook Mechanics and Engineering, vol. 31, no. 6, pp. 1138-1147, 2012.

[14] S.-Q. Yang, Y.-H. Huang, Y.-Y. Jiao, W. Zeng, and Q.-L. Yu, "An experimental study on seepage behavior of sandstone material with different gas pressures," Acta Mechanica Sinica, vol. 31, no. 6, pp. 837-844, 2015.

[15] R. Porras, J. R. Carmona, R. C. Yu, and G. Ruiz, "Experimental study on the fracture of lightly reinforced concrete elements subjected to eccentric compression," Materials and Structures, vol. 49, no. 1-2, pp. 87-100, 2016. 